\title{
Design of a CPW-fed Dual Band-Notched Planar Wideband Antenna for UWB Applications
}

\author{
Fei Yu and Chunhua Wang \\ Hunan University \\ People's Republic of China
}

\section{Introduction}

Since the first Report and Order by the Federal Communications Commission (FCC) authorized the unlicensed use of ultra wideband (UWB) which must meet the emission masks on February 14, 2002 [1], both industry and academia have paid much attention to R\&D of commercial UWB systems. Among UWB system design, the UWB antenna is the key component. Recently, a considerable amount of researches have been devoted to the development of the UWB antenna for its enabling high data transmission rates, low power consumption and simple hardware configuration in communication applications such as radio frequency identification devices, sensor networks, radar, location tracking, etc. Nowadays, the planar printed antenna fed with a microstrip line or a coplanar waveguide $(\mathrm{CPW})$ has received much attention due to its high radiation efficiency and compact size and can be easily integrated with the other circuit. However, compared to the microstrip-fed antennas, the CPW-fed antennas are very good candidates since the feed line and slots are on one side of the substrate [2]. In order to obtain ultra wideband, the different optimum metal radiation patch geometries have been developed, like fork shape [3], elliptical shape [4], square shape [5], spade shape [6], circle shape [7], or made some modifications about the radiation patch [8]. Besides, over the designated frequency band, there exist some narrow bands for other communication systems, such as WiMAX operating in the 3.3 to $3.6 \mathrm{GHz}$ band, and WLAN operating in the 5.15 to $5.825 \mathrm{GHz}$. They may cause communication interference with the UWB system. To solve this problem, it is desirable to design antennas with band notched characteristics to minimise potential interference. Several UWB antennas with frequency band notched function have been reported recently. The reported antennas are generally embedded with a half-wavelength structure such as a $\omega$-shaped slot [2], a Ushaped slot [4], a C-shaped slot [8], or a V-shaped slot [9]. But most reported antennas were designed with only one notched band, mainly discussed on WLAN frequency band 5.15 to $5.825 \mathrm{GHz}$. UWB antennas with dual notched band were recently reported. In [10], the dual notched bands were formed by two nested C-shaped slots embedded in the bevelled patch. A pair of asymmetrical spurlines on the feedline was used to achieve dual notched band in [11]. A recently reported antenna has been designed by making use of two split resonant rings (SRR) to obtain dual band-notched characteristics [12]. Nevertheless, the geometry of the SRR structure is relatively complex.

In this paper, a CPW-fed novel planar ultra-wideband antenna with dual band-notched characteristics is introduced. In order to obtain ultra wideband, some modifications about 
the antenna are introduced. Simply by etching a U-shaped slot in the radiating element, single band-notched characteristic from 5 to $6 \mathrm{GHz}$ can be easily obtained. By etching two nested U-shaped slots in the radiating patch, dual band-notched characteristics for the proposed UWB antenna can be created to reduce the potential interferences between UWB system and narrowband systems. Details of the antenna design and simulation are presented in order to demonstrate the performance of the proposed antennas. Sec. 2 presents the details of the antenna structure and the design procedure. The antennas with single and dual band-notched characteristics were designed in Sec. 3. Sec. 4 analyses the radiation patterns and makes a comparison between recently proposed antennas and this antenna. Finally, the conclusion is presented in Sec. 5 .

\section{UWB antenna design}

It is well known that the rectangular patch antenna has a narrow-band characteristic. To improve its operating bandwidth, we shape the bottom of the patch into an arc. In practical applications, the size of ground plane is finite and the direction of maximum radiation tilts somewhat upwards from the horizontal plane. To reduce this beam tilting, the ground plane of the proposed antenna is designed to have not rectangular but rounded shape. The arc-shaped patch and tapered ground plane make good broadband impedance matching of the antenna possible. To further expand the impedance bandwidth, a right-angle triangle on the upper corners of the patch and a small fan angle on each side of the ground plane near the feeding line are removed respectively. The improvement process steps are shown in Fig. 1.
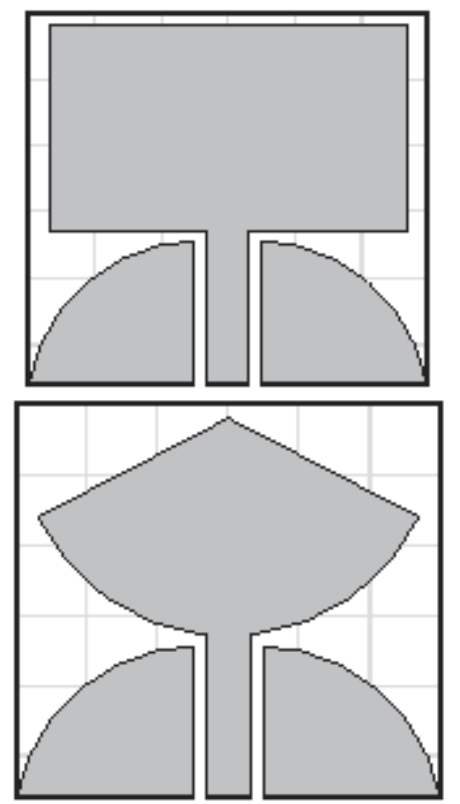
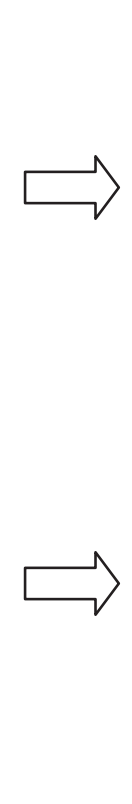
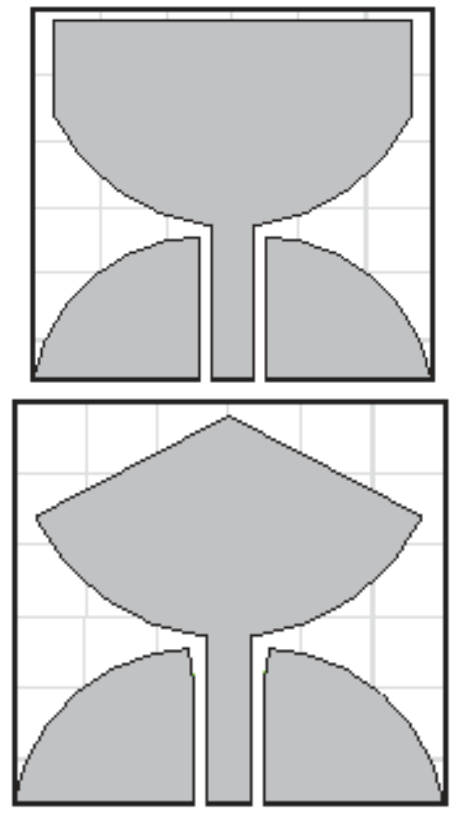

Fig. 1. The improvement process of the antenna 
A comparison of the simulated reflection coefficient (S11) of the antenna with a full rectangular radiating patch, with the modification of the bottom side, with the cuts on the upper corners, and with the small angle on each side of the ground plane is plotted in Fig. 2 when all the dimensions are the same. It can be seen that the first line demonstrates the rectangular patch antenna has a narrow-band characteristic. The second line shows the impedance bandwidth is broadened when the bottom of the patch is shaped into an arc. On the basis of this, the third line about the upper corners modification indicates the bandwidth is further expanded compared with the second line (the main advantages that this modification is reducing the lowest frequency). The fourth line demonstrates the small angle on each side of the ground plane near the feeding line will affect the characteristic impedance of the CPW line and also explains the proposed antenna has a very wide impedance bandwidth.

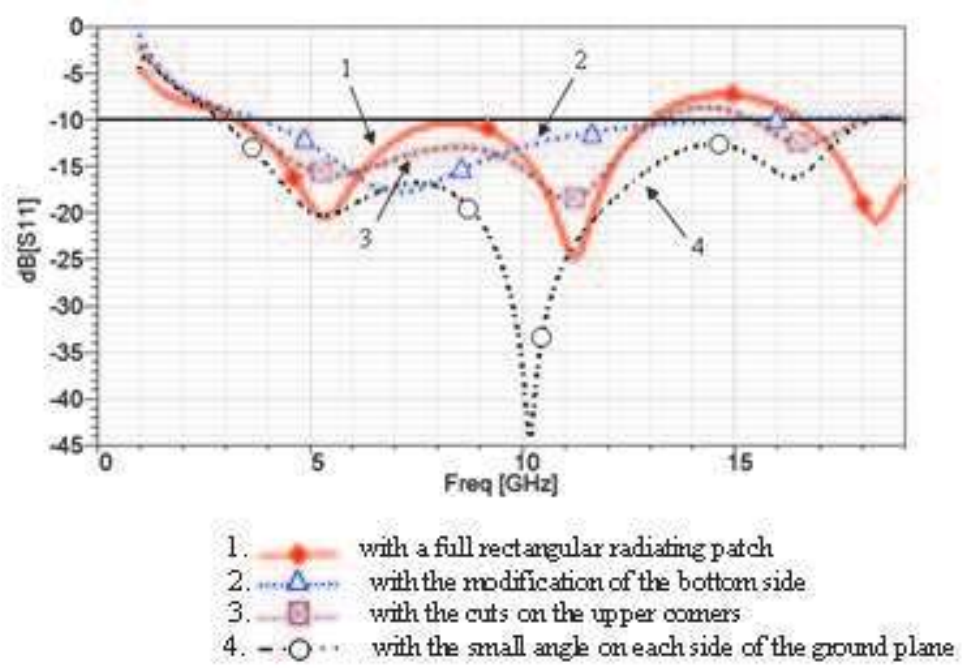

Fig. 2. Simulated reflection coefficient for different shapes of the radiation patch and the ground plane

The final geometry of the proposed compact band-notched antenna is depicted in Fig. 3. The antenna (referred to as antenna A) is printed on a FR4 substrate with size $28 \mathrm{~mm} \times 30 \mathrm{~mm}$, thickness of $1.6 \mathrm{~mm}$, relative permittivity of 4.4 and loss tangent $\tan \delta=0.02$. The proposed antenna is located in $\mathrm{x}-\mathrm{y}$ plane and the normal direction is parallel to $\mathrm{z}$-axis. The center strip and gap of the CPW line are $3.6 \mathrm{~mm}$ and $0.3 \mathrm{~mm}$ to achieve $50-\Omega$ port characteristic impedance. By the improvement steps mentioned above the second paragraph, good impedance matching can be achieved across a wide bandwidth. We optimize the antenna geometrical parameters for $\mathrm{S} 11<-10 \mathrm{~dB}$ over the entire frequency range $(3.1-10.6 \mathrm{GHz})$. The optimisation procedure is done by using Ansoft HFSS software. The final antenna geometry parameters are obtained as L1 $=28 \mathrm{~mm}, \mathrm{~L} 2=30 \mathrm{~mm}, \mathrm{~L} 3=13.5 \mathrm{~mm}, \mathrm{~L} 4=5 \mathrm{~mm}, \mathrm{~L} 5=1.5$ $\mathrm{mm}, \mathrm{L} 6=10.8 \mathrm{~mm}, \mathrm{~L} 7=5.4 \mathrm{~mm}, \mathrm{~L} 8=12.9 \mathrm{~mm}, \mathrm{R}=15 \mathrm{~mm}, \mathrm{~g}=0.7 \mathrm{~mm}, \mathrm{f}=3.6 \mathrm{~mm}, \mathrm{c}=0.3$ $\mathrm{mm}, \mathrm{t}=0.3 \mathrm{~mm}, \mathrm{H}=1.6 \mathrm{~mm}$. By selecting the optimal parameters, the proposed antenna can be tuned to operate within the UWB band. 


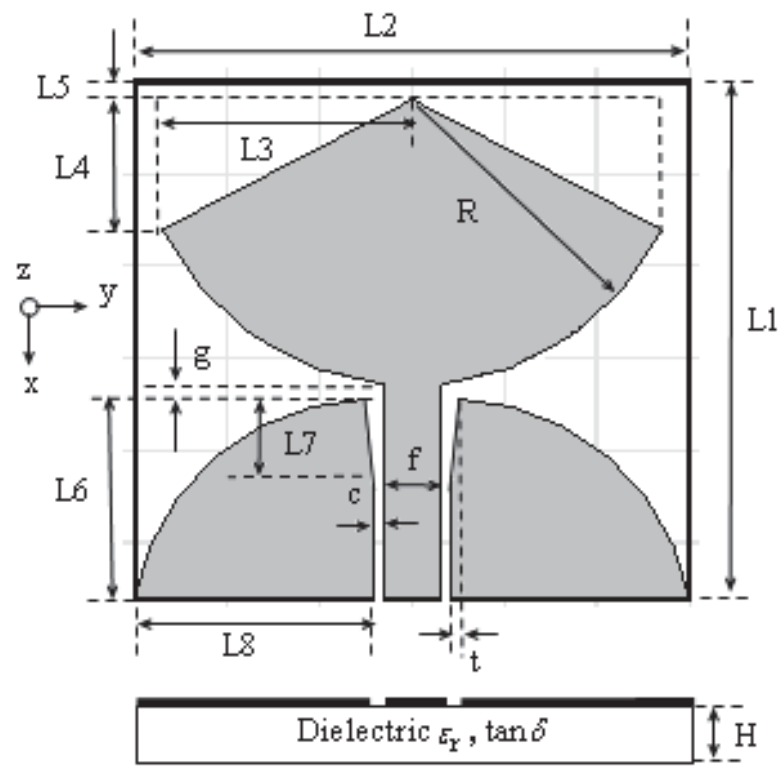

Fig. 3. Configuration of the proposed antenna A

\section{Band-notched UWB antenna design}

\subsection{Single band-notched UWB antenna design}

Interference between the existing narrow band wireless systems and UWB systems has been a concern due to the inherently ultra-wide operating frequency range for UWB communication. Such as IEEE 802.11a in U.S.A (5.15 GHz to $5.35 \mathrm{GHz}, 5.725 \mathrm{GHz}$ to 5.825 $\mathrm{GHz}$ ) and HIPERLAN/2 in Europe (5.15 GHz to $5.35 \mathrm{GHz}, 5.47 \mathrm{GHz}$ to $5.725 \mathrm{GHz}$ ). To overcome this problem, various UWB antennas with a band-notched function have been developed not only to mitigate the potential interference but also to remove the requirement of an extra bandstop filter in the system. The simple and commonly used approach is to incorporate slots into the antennas' main radiator. Fig. 4 shows a schematic diagram of the UWB planar antenna (referred to as antenna B) with filtering property operating in the 5 to 6 $\mathrm{GHz}$ band.

The band-notched operation is achieved by using a U-shaped slot in the radiating patch of antenna A. Note that when the band-notched design applied to antenna A, there is no retuning work required for the previously determined dimensions. The notch frequency given the dimensions of the bandnotched feature can be given as

$$
\mathrm{f}_{\text {notch }}=\frac{c}{2 L \sqrt{\varepsilon_{e f f}}}
$$

Where $L$ is the total length of the U-shaped slot, $\varepsilon_{\text {eff }}$ is the effective dielectric constant, and $c$ is the speed of the light. We can take (1) into account in obtaining the total length of the U-shaped slot at the very beginning of the design and then adjust the geometry for the final 


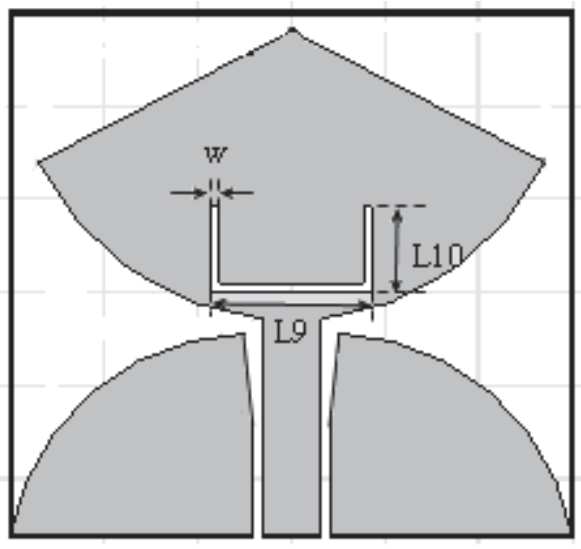

Fig. 4. Configuration of the proposed antenna B

design. From (1), we can known the length of the U-shaped slot $(\mathrm{L}=\mathrm{L} 9+2 \mathrm{~L} 10)$ is a crucial parameter to determine the center frequency of the stop band. In this design, the U-shaped slot was chosen to be nonresponsive close to about $0.33 \lambda$ at the center frequency of the desired notched-band, where $\lambda$ is the wavelength at the center frequency of the rejection band, the final design parameters of the U-shaped slot are L9 $=8.6 \mathrm{~mm}, \mathrm{~L} 10=4.6 \mathrm{~mm}, \mathrm{w}=$ $0.2 \mathrm{~mm}$.

The impedance performance of the designed antenna was simulated using electromagnetic software Ansoft HFSS 11 which is based on finite element analysis. The simulated VSWR is shown in Fig. 5. The result demonstrates that a stop-band can be obtained by inserting a Ushaped slot in radiating patch. Compared to antenna A design, the single band-notched UWB antenna successfully blocks out the 5 to $6 \mathrm{GHz}$ band and still performs good impedance-matching at other frequencies in the UWB band. Fig. 6 shows the simulated current distributions at specific frequencies. In Fig. 6(a) and (c), at frequencies 3.5 and 7.5 $\mathrm{GHz}$, the current distributions mainly flow along the transmission line; while around the Ushaped slot the current is small. The simulated current distribution at $5.5 \mathrm{GHz}$ is shown in

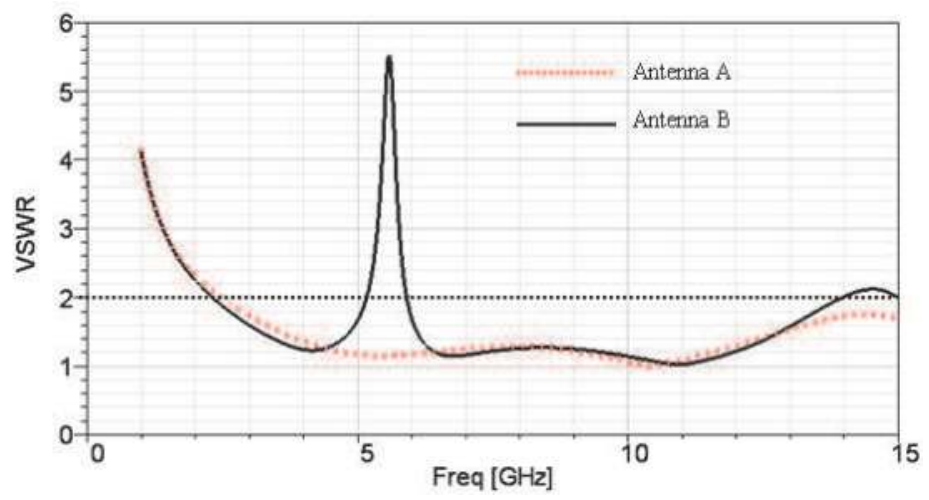

Fig. 5. Simulated VSWR of antenna B compared to antenna A 

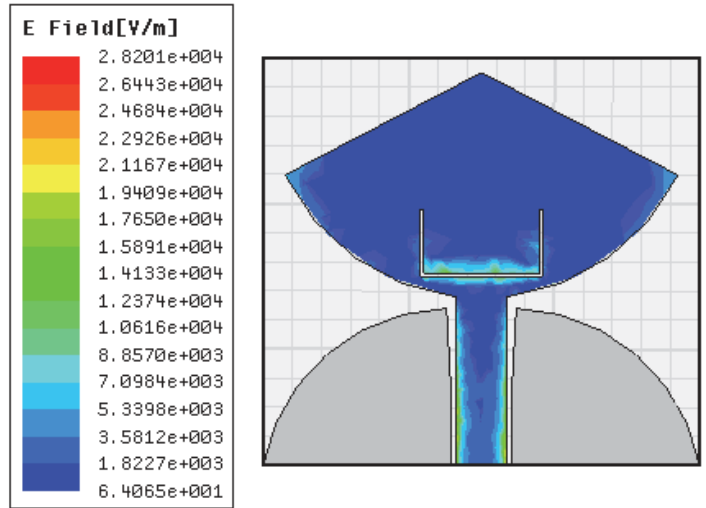

(a) $3.5 \mathrm{GHz}$
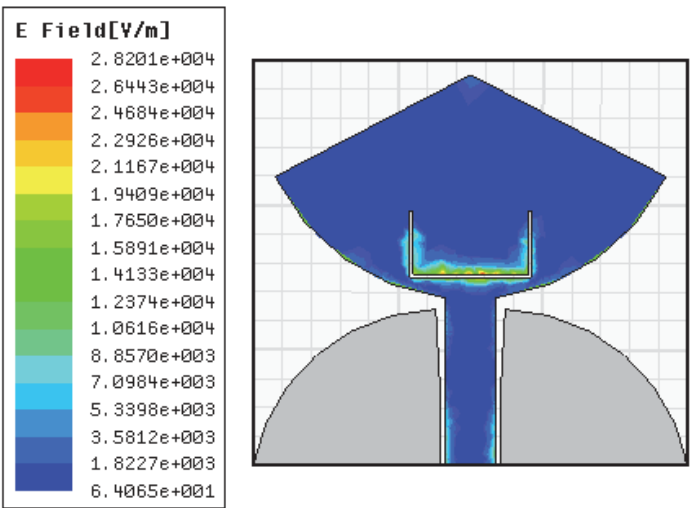

(b) $5.5 \mathrm{GHz}$

\section{E Field $[\mathrm{Y} / \mathrm{m}]$}
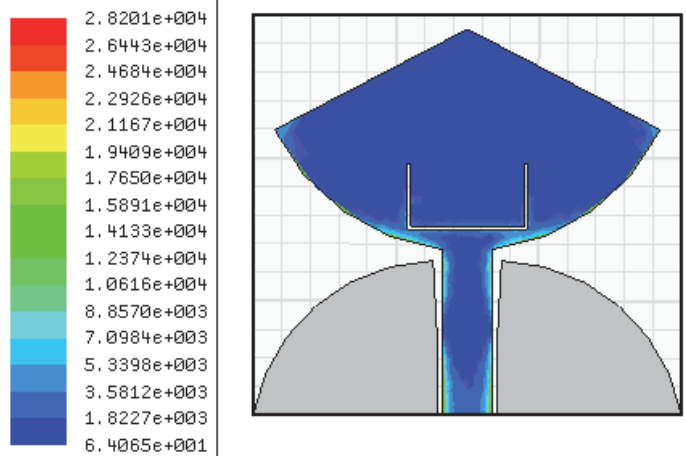

(c) $7.5 \mathrm{GHz}$

Fig. 6. Simulated current distribution of antenna B at specific frequencies

Fig. 6(b). It reveals that the currents mainly concentrate over the area of the slot in the radiation patch. The impedance nearby the feed-point changes acutely making large 
reflection at the desired notched frequency. Fig. 7 also shows the surface current around the slot of antenna B at the notch frequency at $5.5 \mathrm{GHz}$. At $5.5 \mathrm{GHz}$, current is around the Ushaped slot. The impedance is nearly zero at the top of slot and the impedance is very high nearby the antenna feeding. In this case, the high impedance at the feeding point leads to the desired impedance mismatching near the notch frequency at $5.5 \mathrm{GHz}[10]$.

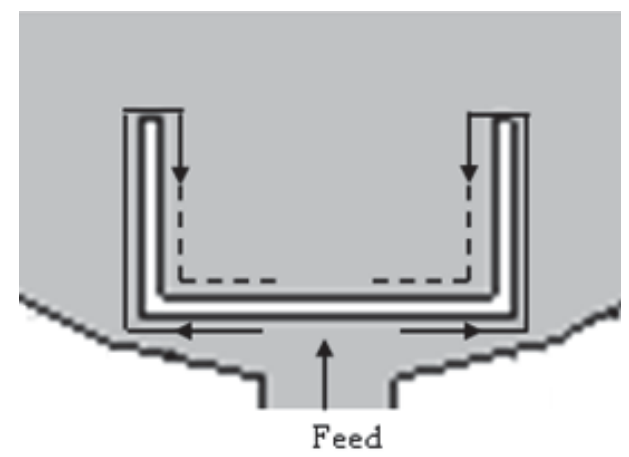

Fig. 7. Surface current around the slot of antenna B at the notch frequency at $5.5 \mathrm{GHz}$

By tuning various parameters, we can control the resonance frequency and quality factor to confirm the stop band. L9, L10 and w are key parameters to tune when the others are fixed. The effects of the lengths (L19, L10) and width (w) of the U-shaped slot on band-notched performance of the antenna are analyzed below. Fig. 8 illustrates the VSWR for different values of L9, It is obvious that when L9 becomes larger, the central frequency is reduced, and the edge of low frequency and the bandwidth are nearly unchanged. Fig. 9 shows the band-notch characteristics with different L10, the behavior is similar to changing L9. When L10 is increasing from $4.1 \mathrm{~mm}$ to $5.1 \mathrm{~mm}$, the edge of low frequency and the bandwidth is nearly unchanged. However, the central frequency of the notched band is decreased. In Fig. 10 , the central frequency increases as $w$ increases. The bandwidth is shortened when the width $(\mathrm{w})$ of the slot decreases from $0.3 \mathrm{~mm}$ to $0.1 \mathrm{~mm}$. The antenna gain of the antenna $B$ is shown in Fig. 11. The figure indicates that, the proposed antenna has good gain flatness except for in the stop-band. The antenna gain variations are less than $4 \mathrm{~dB}$ throughout the desired UWB frequency band, and a sharp gain drop of about $7 \mathrm{~dB}$ occurs at $5.5 \mathrm{GHz}$.

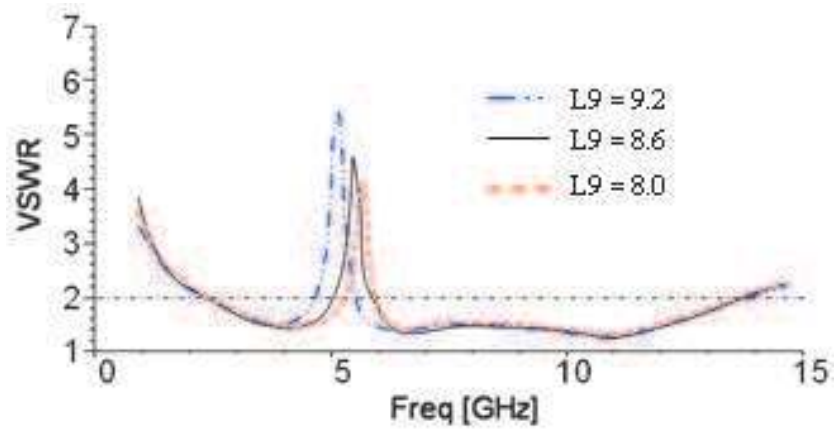

Fig. 8. Simulated VSWR for various L9 when L10 $=4.6 \mathrm{~mm}$ and $\mathrm{w}=0.2 \mathrm{~mm}$ 


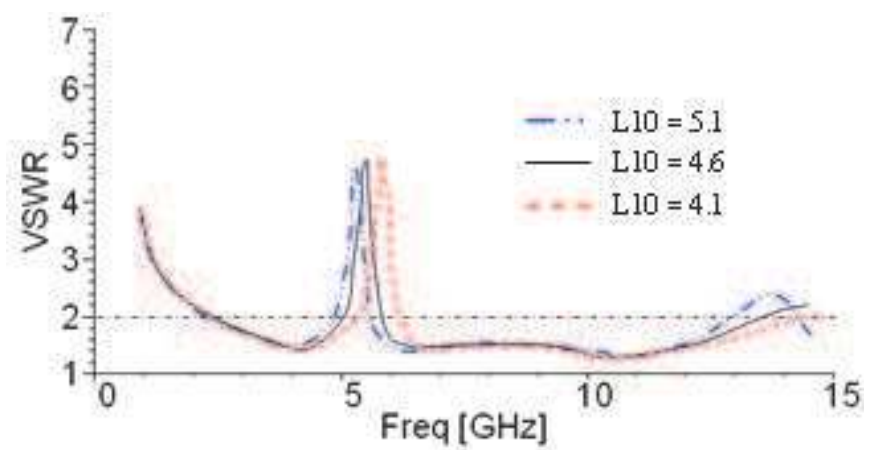

Fig. 9. Simulated VSWR for various L10 when L9 $=8.6 \mathrm{~mm}$ and $\mathrm{w}=0.2 \mathrm{~mm}$

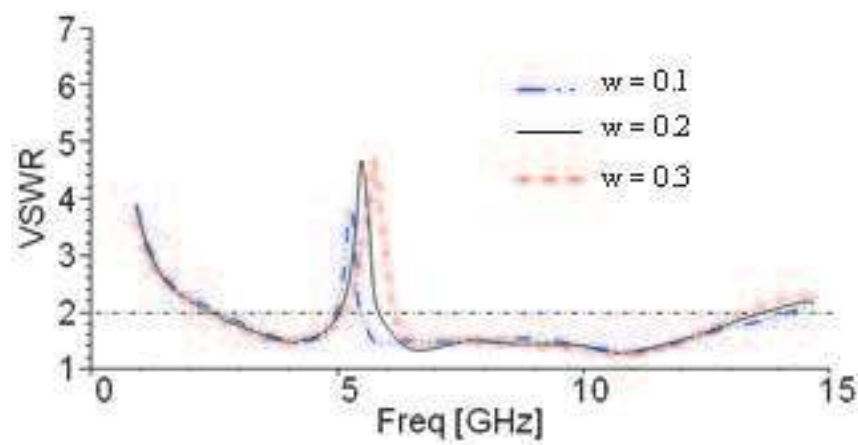

Fig. 10. Simulated VSWR for various $\mathrm{w}$ when $\mathrm{L} 9=8.6 \mathrm{~mm}$ and $\mathrm{L} 10=4.6 \mathrm{~mm}$

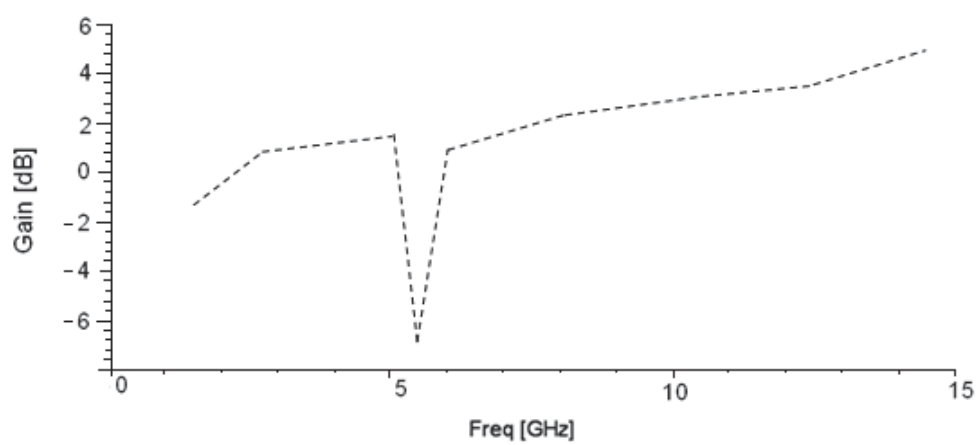

Fig. 11. Simulated gain of antenna B

To further explain the principle of the band-notched structures and how the center frequencies and bandwidths can be controlled an LC circuit model has been extracted for the proposed antenna A as shown in Fig. 12. Approximately, the radiating element of UWB antenna can be seen as several RLC parallel cells in series. The equivalent circuit input impedance can be expressed as 


$$
Z_{R}=\sum_{k=1}^{n} \frac{j \omega R_{k} L_{k}}{R_{k}\left(1-\omega^{2} C_{k} L_{k}\right)+j \omega L_{k}}
$$

To simplify the calculation, only the real part is considered to determine the values of components with the formula

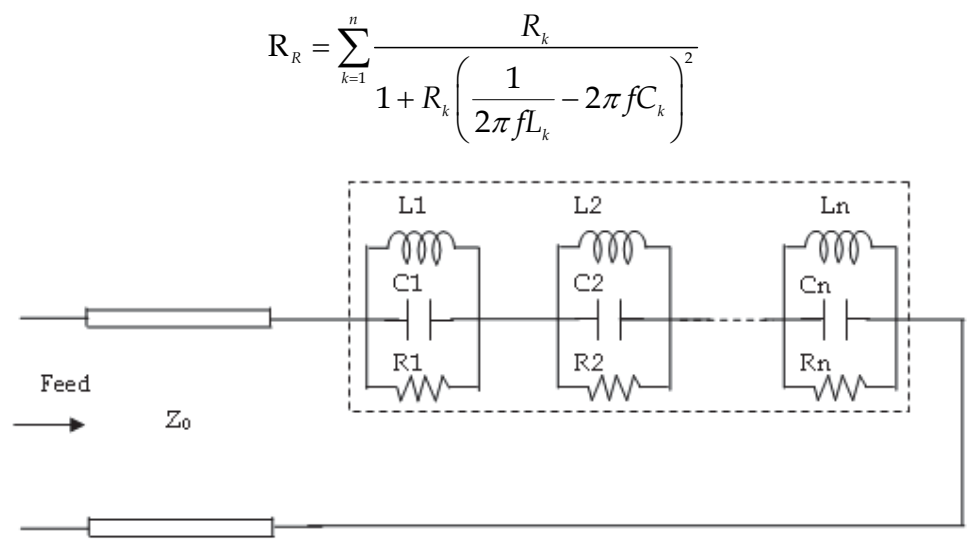

Fig. 12. Impedance model for radiating element of UWB antenna A

Fig. 13 shows the equivalent circuit model for radiating element of UWB antenna B. Le and $\mathrm{Ce}$ indicate the inductor and capacitor values of the slot resonator. When the current propagates along the edge of the slot, an inductance should be introduced to the model. The narrow slot is equivalent to a capacitor. Increasing the length of the slot or decreasing the slot width is similar to increasing the capacitor value in the parallel LC circuit. On the other hand, increasing the length of slot will also lead to the increase of the inductor value [13]. Next we discuss bandwidth adjustment. For the parallel RLC resonator circuit as shown in Fig. 13, the input admittance is given by

$$
\mathrm{Y}_{\mathrm{in}}=\frac{1}{\mathrm{R}_{\mathrm{R}}}+j \omega \mathrm{C}_{e}+\frac{1}{j \omega L_{e}}
$$

Where $R_{R}$ represents the radiation resistance of the monopole element of antenna A. For a frequency near the resonant frequency [13]

$$
\begin{aligned}
\omega & =\omega_{0}+\Delta \omega, \omega_{0}=\frac{1}{L_{e} C_{e}} \\
Y_{\text {in }} & =\frac{1}{R_{R}}+j \omega C_{e}+\frac{1}{j \omega L_{e}} \\
& =\frac{1}{R_{R}}+\frac{j}{\omega L_{e}}\left(\omega^{2} L_{e} C_{e}-1\right) \\
& =\frac{1}{R_{R}}+\frac{j}{\omega L_{e}}\left(2 \omega_{0} \Delta \omega+\Delta \omega^{2}\right) L_{e} C_{e} \\
& \approx \frac{1}{R_{R}}+j 2 C_{e} \Delta \omega
\end{aligned}
$$


In this case it is obvious that $Y_{\text {in }}$ is similar to the input admittance of a parallel $\mathrm{R}$ and $2 \mathrm{C}$ circuit near $0 \mathrm{GHz}$. Then the $-3 \mathrm{~dB}$ bandwidth (BW) of the parallel RLC resonant circuit approximately equals twice the $-3 \mathrm{~dB}$ bandwidth of the parallel $\mathrm{R}$ and $2 \mathrm{C}$ circuit as shown in below [13]

$$
\begin{gathered}
\mathrm{BW}=\frac{2}{\mathrm{R}_{R} \times 2 C_{e}}=\frac{1}{\mathrm{R}_{R} C_{e}} \\
F B W=\frac{\mathrm{BW}}{\omega_{0}}=\frac{1}{\omega_{0} \mathrm{R}_{R} C_{e}}
\end{gathered}
$$

Where FBW represents the fractional bandwidth. Based on the above analysis we have a clear method for controlling the centre frequency and bandwidth of the notch. Increasing the length of the slots, which is similar to increasing the inductor value and the capacitor value, has the effect of decreasing the centre frequency and bandwidth [13]. Simulated results shown in Figs. 8 and 9 prove this conclusion. Fig. 10 shows the simulated VSWR for various width of the slot. It can be seen that, increasing the slot width is equivalent to decreasing the capacitor value, which ultimately leads to the rise of centre frequency and bandwidth of the notch band.

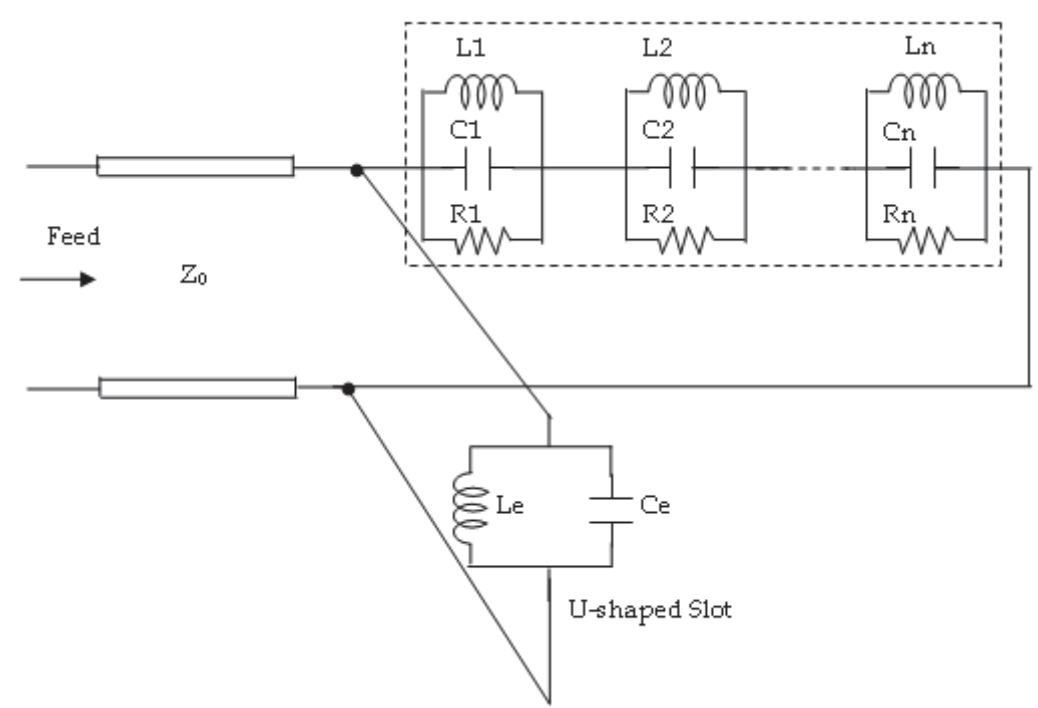

Fig. 13. Impedance model for radiating element of UWB antenna B

\subsection{Dual band-notched UWB antenna design}

Besides WLAN systems, IEEE 802.16 WiMAX from 3.3 to $3.6 \mathrm{GHz}$ also operates in the UWB band. Dual notched bands are realized by using two nested U-shaped slots in the radiating patch (antenna A), which can yield band-notched characteristics centered at $3.4 \mathrm{GHz}$ and 5.5 GHz. Fig. 14 shows the geometry and configuration of the UWB antenna (referred to as antenna C) with dual band-notched characteristics. It is note that, since the mutual coupling 
exists between the exterior and interior $U$-shaped slots, the simulation values are not exactly equal to the prediction ones [10]. The optimized design parameters are L11 $=5 \mathrm{~mm}, \mathrm{~L} 12=11$ $\mathrm{mm}, \mathrm{L} 13=5.1 \mathrm{~mm}, \mathrm{~L} 14=10 \mathrm{~mm}, \mathrm{w} 1=0.3 \mathrm{~mm}$.

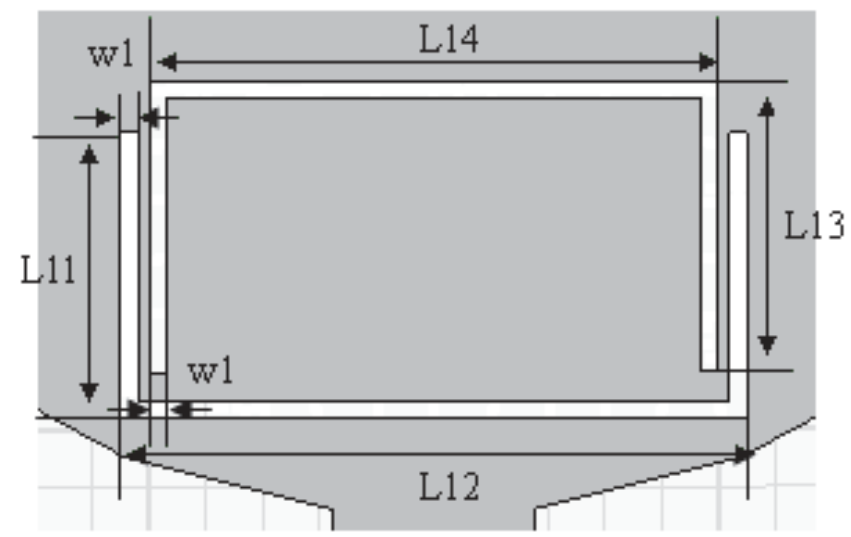

Fig. 14. Configuration of the proposed antenna $C$

Fig. 15 shows the simulated VSWR against frequency for the proposed antenna C. Results of the reference antennas without band-notched characteristics and with single band-notched characteristic are also shown for comparison. It is seen that the proposed antenna exhibits two notched bands of 3.3 to 3.5 and 5 to $6 \mathrm{GHz}$, while maintaining wideband performance from 1.8 to $15 \mathrm{GHz}$ for VSWR $<2$, covering the entire UWB frequency band. It is concluded that the notch bands for antenna $C$ are indeed created by the two nested U-shaped slots. The simulated gain is shown in Fig. 16 and indicates a gain variation from 0.5 to $4.2 \mathrm{~dB}$ in the frequency range of 1.8 to $15 \mathrm{GHz}$. As can be expected, Sharp gain decreases occur both in 3.3 to 3.5 and 5 to $6 \mathrm{GHz}$ bands. However, for other frequencies outside the rejected bands, the antenna gain is nearly constant in the entire UWB band. Fig. 17 shows the axial ratio against theta (spherical coordinate) for the proposed antenna $C$. It is observed that the whole axial ratio is greater than $3 \mathrm{~dB}$, so the proposed antenna $\mathrm{C}$ is a linearly polarized antenna.

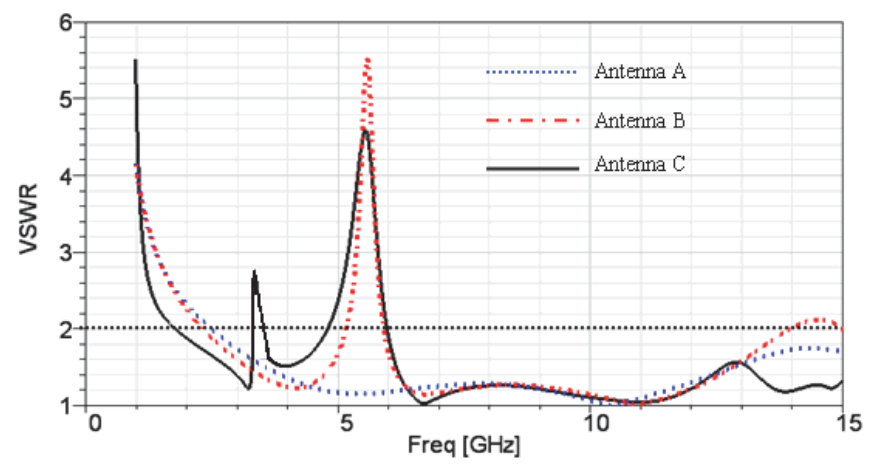

Fig. 15. Simulated VSWR of antenna C compared to antenna A and B 


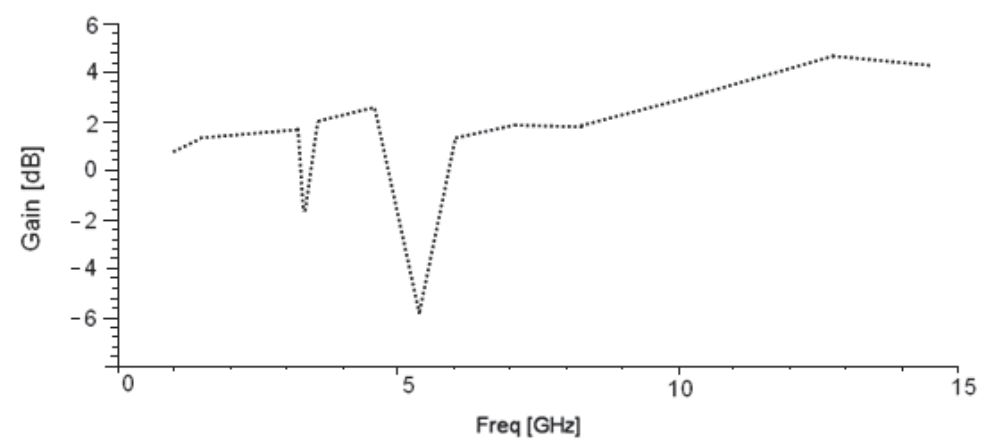

Fig. 16. Simulated gain of antenna C

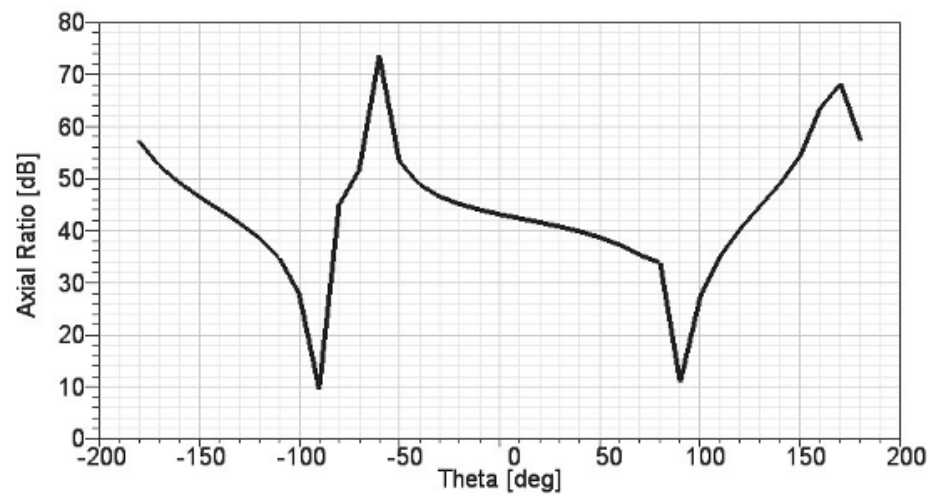

Fig. 17. Simulated axial ratio of antenna C

\section{Radiation patterns and comparison}

From the UWB applications point of view, the UWB antennas are usually required to have an omnidirectional radiation in the plane orthogonal to the radiating element. The radiation patterns at specific frequencies $3.2 \mathrm{GHz}, 6 \mathrm{GHz}, 9 \mathrm{GHz}, 10.6 \mathrm{GHz}$ and $13.5 \mathrm{GHz}$ are simulated and illustrated in Fig. 18. The quasi-omnidirectional and symmetrical patterns in $\mathrm{H}$ plane in the whole band are obtained, which are necessary in a UWB communication system. The interference of high modes in high frequency is reduced. As a result, the proposed antenna can be used in several applications to compensate the drawback of the antennas at the whole frequency band from 3.1 to $10.6 \mathrm{GHz}$.

It is note that, the radiation patterns of antenna A and antenna B are not depicted. From the analysis by the Reference [10], the proposed band-notched structures including the single band-notched and dual band-notched ones have little influence on the radiation patterns of the UWB antenna. Tab. 1 summarizes the performances and compares this design to recently published UWB antennas with stop-band characterization. From Tab. 1, we can see that some of the antennas have only one notched band; others which have two notched bands, but the operation frequency band is not wide. When comparing the results to the 
performance of some UWB antennas presented in Tab. 1, the following features of the implemented antenna can be highlighted: wide impedance bandwidth, good band-notch characteristic, compact in size and good gain flatness.

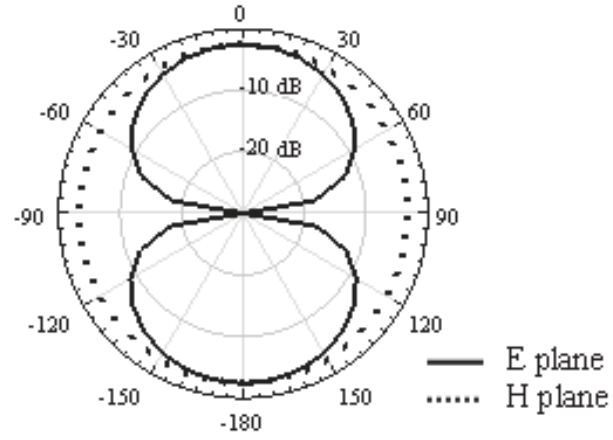

(a) $3.2 \mathrm{GHz}$

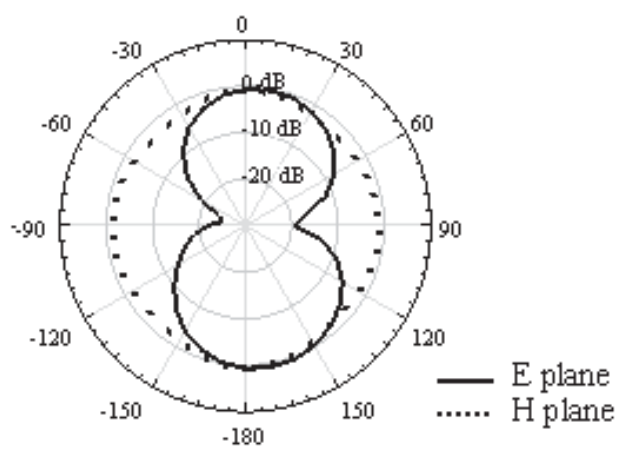

(c) $9 \mathrm{GHz}$

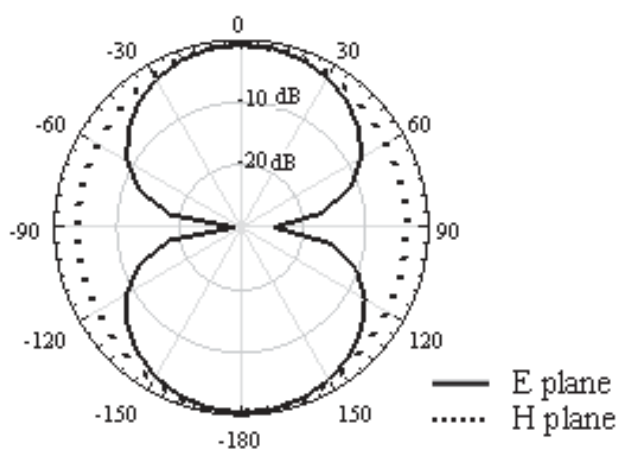

(b) $6 \mathrm{GHz}$

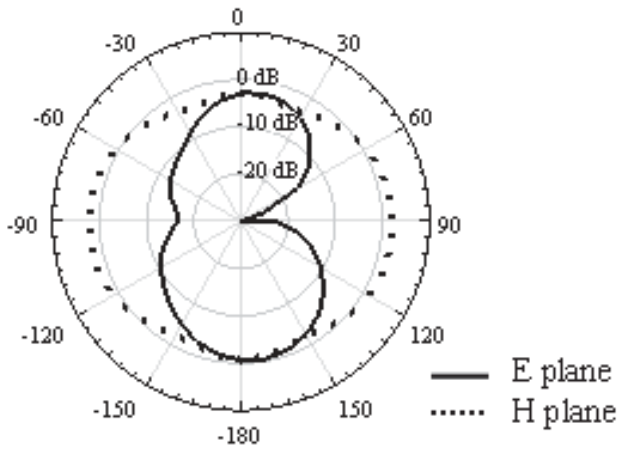

(d) $10.6 \mathrm{GHz}$

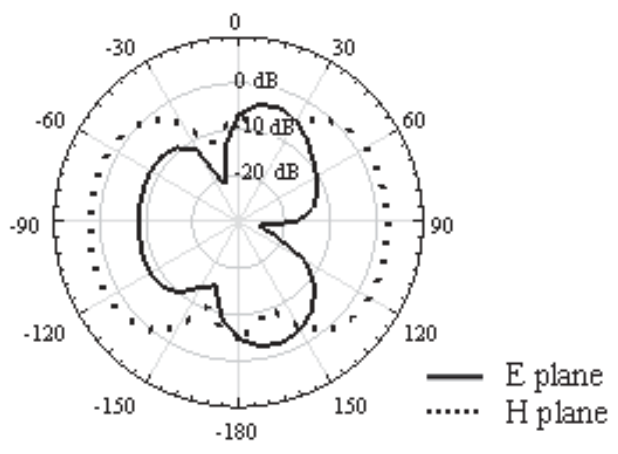

(e) $13.5 \mathrm{GHz}$

Fig. 18. Simulated radiation patterns at specific frequencies 


\begin{tabular}{|c|c|c|c|c|c|c|c|}
\hline Authors & $\begin{array}{l}\text { Substrate } \\
\text { material }\end{array}$ & $\begin{array}{l}\text { Method of } \\
\text { achieve } \\
\text { stop-band }\end{array}$ & $\begin{array}{c}\text { Operating } \\
\text { bandwidth } \\
(\mathrm{GHz})\end{array}$ & $\begin{array}{c}\text { Relative } \\
\text { bandwidth }\end{array}$ & $\begin{array}{c}\text { Stop-band } \\
\text { bandwidth } \\
(\mathrm{GHz})\end{array}$ & $\begin{array}{l}\text { Antenna } \\
\text { size } \\
\left(\mathrm{mm}^{2}\right)\end{array}$ & $\begin{array}{l}\text { Gain } \\
(\mathrm{dB})\end{array}$ \\
\hline $\begin{array}{c}\text { Mehdipour, } \\
\text { A. et al }\end{array}$ & $\begin{array}{c}\text { Rogers } \\
\text { RT } \\
\text { Duroid } \\
3003 \\
\end{array}$ & $\begin{array}{l}\text { embedding a } \\
\omega \text {-shaped slot }\end{array}$ & $3.0-11$ & $114 \%$ & $5.4-5.95$ & $35 \times 35$ & --- \\
\hline $\begin{array}{l}\text { Nikolaou, } \\
\text { S. et al }\end{array}$ & $\begin{array}{c}\text { liquid } \\
\text { crystal } \\
\text { polymer }\end{array}$ & $\begin{array}{l}\text { inserting a U- } \\
\text { shaped slot }\end{array}$ & $3.0-12$ & $120 \%$ & $5.0-6.0$ & $\begin{array}{c}38.7 \times \\
26.88\end{array}$ & $<4.2$ \\
\hline $\mathrm{Yu}$, F. et al & FR4 & $\begin{array}{c}\text { embedding a } \\
\text { C-shaped } \\
\text { slot }\end{array}$ & $3.0-23$ & $153.8 \%$ & $5.0-6.0$ & $28 \times 30$ & $0.2-3.9$ \\
\hline Kim, Y. et al & FR4 & $\begin{array}{l}\text { inserting a V- } \\
\text { shaped slot }\end{array}$ & $2.8-10.6$ & $116.4 \%$ & $f_{c}=5.25$ & $22 \times 31$ & $0.8-5.0$ \\
\hline $\begin{array}{c}\text { Chu, Q.-X. } \\
\text { et al }\end{array}$ & FR4 & $\begin{array}{l}\text { embedding } \\
\text { two nested C- } \\
\text { shaped slots }\end{array}$ & $3.1-10.6$ & $>91.3 \%$ & $\begin{array}{l}\mathrm{f}_{\mathrm{c} 1}=3.4 \\
\mathrm{f}_{\mathrm{c} 2}=5.5\end{array}$ & $26 \times 30$ & $2-5$ \\
\hline Luo, J. et al & FR4 & $\begin{array}{l}\text { embedding } \\
\text { an E-shaped } \\
\text { slot in the } \\
\text { patch and a } \\
\text { U-shaped slot } \\
\text { in the ground }\end{array}$ & $2.87-10.91$ & $116.6 \%$ & $\begin{array}{l}3.49-4.12 \\
5.66-6.43\end{array}$ & $35 \times 14$ & ---- \\
\hline This work & FR4 & $\begin{array}{l}\text { embedding } \\
\text { two nested } \\
\text { U-shaped } \\
\text { slots }\end{array}$ & $1.8-15$ & $>157.1 \%$ & $\begin{array}{l}\mathrm{f}_{\mathrm{c} 1}=3.4 \\
\mathrm{f}_{\mathrm{c} 2}=5.5\end{array}$ & $28 \times 30$ & $0.5-4.2$ \\
\hline
\end{tabular}

Table 1. Comparison between recently proposed antennas and this antenna

\section{Conclusion}

In this paper, a CPW-fed novel planar ultra-wideband antenna with dual band-notch characteristics was presented. One right-angle triangle was simulation removed from both two upper corners of the rectangular UWB antenna combined with an arc-shaped bottom and with a tapered arc-shaped ground plane. The simulation result of the VSWR demonstrates that the antenna has very broadband impedance which covers the frequency range of 1.8 to over $15 \mathrm{GHz}$. By embedding two nested U-shaped slot in the radiating patch, two frequency band notches between the bandwidth of 3.3 to $3.5 \mathrm{GHz}$ and 5 to $6 \mathrm{GHz}$ for WiMAX and WLAN have been obtained. Stable radiation patterns and constant gain in the UWB band are also obtained. Simulated and analyzed in detail in this paper, the proposed antenna could be a good candidate for UWB communication applications. 


\section{Acknowledgment}

The authors would like to thank the reviewers for their professional comments and suggestion. They also thank CEO Lazinica Aleksandar from InTech for his valuable suggestions in revising this paper and Prof. Viktorija Zgela for his assistance in improving the manuscript quality. They are also grateful to their family for selfless help.

\section{References}

First Report and Order. (2002). Revision of Part 15 of the Commission's Rule Regarding Ultra-Wideband Transmission System FCC 02-48. Federal Communications Commission

Mehdipour, A.; Parsa, A.; Sebak, A.-R. \& Trueman, C. W. (2009). Miniaturised coplanar waveguide-fed antenna and band-notched design for ultra-wideband applications. IET Microwave Antennas and Propagation, Vol. 3, No. 6, pp. 974-986, ISSN 1751-8725

Ryu, K. S. \& Kishk, A. A. (2009). UWB Antenna With Single or Dual Band-Notches for Lower WLAN Band and Upper WLAN Band. IEEE Transactions on Antennas and Propagation, Vol. 57, No. 12, pp. 3942-3950, ISSN 0018-926X

Nikolaou, S.; Kingsley, N. D.; Ponchak, G. E.; Papapolymerou, J. \& Tentzeris, M. M. (2009). UWB Elliptical Monopoles With a Reconfigurable Band Notch Using MEMS Switches Actuated Without Bias Lines. IEEE Transactions on Antennas and Propagation, Vol. 57, No. 8, pp. 2242-2251, ISSN 0018-926X

Ojaroudi, M.; Ghobadi, C. \& Nourinia, J. (2009). Small Square Monopole Antenna With Inverted T-Shaped Notch in the Ground Plane for UWB Application. IEEE Antennas and Wireless Propagation Letters, Vol. 8, pp. 728-731, ISSN 1536-1225

Li, W.-T.; Shi, X.-W. \& Hei, Y.-Q. (2009). Novel Planar UWB Monopole Antenna With Triple Band-Notched Characteristics. IEEE Antennas and Wireless Propagation Letters, Vol. 8, pp. 1094-1098, ISSN 1536-1225

Dong, Y.-J.; Hong, W.; Kuai, Z.-Q. \& Chen, J.-X. (2009). Analysis of Planar Ultrawideband Antennas With On-Ground Slot Band-Notched Structures. IEEE Transactions on Antennas and Propagation, Vol. 57, No. 7, pp. 1886-1893, ISSN 0018-926X

Yu, F. \& WANG, C. (2009). A CPW-Fed Novel Planar Ultra-Wideband Antenna with a Band-Notch Characteristic. Radioengineering, Vol. 18, No. 4, pp. 551-555, ISSN 12102512.

Kim, Y. \& Kwon, D.-H. (2004). CPW-fed planar ultra wideband antenna having a frequency band notch function. Electronics Letters, Vol. 40, No. 7, pp. 403-405, ISSN 0013-5194

Chu, Q.-X. \& Yang, Y.-Y. (2008). A Compact Ultrawideband Antenna With 3.4/5.5 GHz Dual Band-Notched Characteristics. IEEE Transactions on Antennas and Propagation, Vol. 56, No. 12, pp. 3637-3644, ISSN 0018-926X

Zhao, Y. H.; Xu, J. P. \& Yin, K. (2008). Dual band-notched ultra-wideband microstrip antenna using asymmetrical spurlines. Electronics Letters, Vol. 44, No. 18, pp. 10511052, ISSN 0013-5194

Luo, J.; Cui, Z.; Xiong, J.-P.; Zhang, X.-M. \& Jiao Y.-C. (2008). Compact printed ultrawideband monopole antenna with dual band-notched characteristics. Electronics Letters, Vol. 44, No. 19, pp. 1106-1107, ISSN 0013-5194 
Dong, Y. D.; Hong, W.; Kuai Z. Q. \& Chen J. X. (2009). Analysis of Planar Ultrawideband Antennas With On-Ground Slot Band-Notched Structures. IEEE Transactions on Antennas and Propagation, Vol. 57, No. 7, pp. 1886-1893, ISSN 0018-926X 


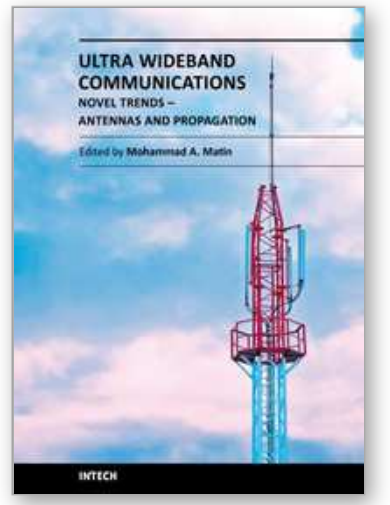

\section{Ultra Wideband Communications: Novel Trends - Antennas and Propagation}

Edited by Dr. Mohammad Matin

ISBN 978-953-307-452-8

Hard cover, 384 pages

Publisher InTech

Published online 09, August, 2011

Published in print edition August, 2011

This book explores both the state-of-the-art and the latest achievements in UWB antennas and propagation. It has taken a theoretical and experimental approach to some extent, which is more useful to the reader. The book highlights the unique design issues which put the reader in good pace to be able to understand more advanced research.

\section{How to reference}

In order to correctly reference this scholarly work, feel free to copy and paste the following:

Fei Yu and Chunhua Wang (2011). Design of a CPW-Fed Dual Band-Notched Planar Wideband Antenna for UWB Applications, Ultra Wideband Communications: Novel Trends - Antennas and Propagation, Dr. Mohammad Matin (Ed.), ISBN: 978-953-307-452-8, InTech, Available from:

http://www.intechopen.com/books/ultra-wideband-communications-novel-trends-antennas-andpropagation/design-of-a-cpw-fed-dual-band-notched-planar-wideband-antenna-for-uwb-applications

\section{INTECH}

open science | open minds

\section{InTech Europe}

University Campus STeP Ri

Slavka Krautzeka 83/A

51000 Rijeka, Croatia

Phone: +385 (51) 770447

Fax: +385 (51) 686166

www.intechopen.com

\section{InTech China}

Unit 405, Office Block, Hotel Equatorial Shanghai

No.65, Yan An Road (West), Shanghai, 200040, China 中国上海市延安西路65号上海国际贵都大饭店办公楼 405 单元

Phone: +86-21-62489820

Fax: +86-21-62489821 
(C) 2011 The Author(s). Licensee IntechOpen. This chapter is distributed under the terms of the Creative Commons Attribution-NonCommercialShareAlike-3.0 License, which permits use, distribution and reproduction for non-commercial purposes, provided the original is properly cited and derivative works building on this content are distributed under the same license. 